\title{
A comparative study of martensite crystal lattice in nanostructured, quenched and deformed Ti-Ni shape memory alloys
}

\author{
S.D. Prokoshkin ${ }^{\mathrm{a}}$, A.V. Korotitskiy, V. Brailovski ${ }^{1}$, K.E. Inaekyan ${ }^{1}$ and S.M. Dubinskiy \\ Department of Plastic Deformation of Special Alloys, Moscow Institute of Steel and Alloys, 4, Leninsky prosp., \\ Moscow 119049, Russia \\ ${ }^{1}$ Mechanical Engineering Department, Ecole de Technologie Superieure, 1100, Notre-Dame Street West, Montreal, \\ H3C 1K3, Canada
}

\begin{abstract}
The crystal lattices of cooling-induced (thermal) martensites formed in thermally and thermomechanically treated Ti-Ni Shape Memory Alloys (SMA) and stress-induced, reoriented and plastically deformed martensites were studied using the X-ray diffraction method. The linear dependences of the quenched B19'-martensite lattice parameters (LPs), maximum transformation lattice strain in single- and polycrystalline B2-austenites as well as its crystallographic direction on nickel concentration in the hyperequiatomic range are presented. The lattice parameters and maximum transformation lattice strain of martensite formed from nanocrystalline or polygonized austenites differ from those of quenched martensite formed from recrystallized austenite. The averaged LPs of stress-induced, reoriented and moderately plastically deformed martensites are close to the lattice parameters of quenched martensite.
\end{abstract}

\section{Introduction}

In binary Ti-Ni SMA, a parent B2-austenite transforms to a monoclinic B19'-martensite (directly or through an intermediate rhombohedral R-phase) under loading, and then the B19'-martensite transforms to the B2-austenite (also directly or through the R-phase) under further heating or unloading [1-3]. Thus, the martensite lattice parameters (LPs) are important parameters of SMA as they determine a maximum martensitic transformation lattice strain $\varepsilon_{\max }$, which is a natural limit for recovery strain. Any changes in the martensite LPs, as a consequence of internal causes or under external actions, are to be taken into consideration if one wishes to maximize strain recovery.

The LPs of the monoclinic B19'-martensite in binary Ti-Ni SMA were first determined in [4]. The reversible changes of the martensite LPs with temperature were found to be anisotropic: the values of $a, c$ and $\beta$ angle increase while $b$ decreases on cooling, accompanied, however, by the normal decrease of the unit cell volume $\omega=a b c \cdot \sin \beta$ $[5,6]$. For quenched alloys, a concentration dependence of both the martensite LPs and $\varepsilon_{\max }$ exists in a hyperequiatomic nickel concentration range: $a, c, \beta$ and $\omega$ decrease and $b$ increases as nickel concentration increases [6-8].

However, the following additional questions should be answered:

(1) Are these dependences linear or stepped [7]?

(2) Do these dependences concern not only the maximum transformation lattice strain, but also its crystallographic direction?

(3) How do the concentration dependences of the maximum transformation strain for austenite single crystals differ from that of the polycrystalline austenite?

A thermomechanical treatment comprising cold rolling (CR) and post-deformation annealing (PDA) which creates a well-developed dislocation substructure or, even better, a nanocrystalline structure in the parent austenite, is an effective method for improving a combination of the SMA functional properties $[1-3,9,10]$.

a e-mail: prokoshkinetmo.misis.ru

This is an Open Access article distributed under the terms of the Creative Commons Attribution-Noncommercial License (http://creativecommons.org/licenses/by-nc/3.0/), which permits unrestricted use, distribution, and reproduction in any noncommercial medium, provided the original work is properly cited. 
Thus, it is important to know the theoretical limit for the recovery strain to which one should strive in the case of the thermomechanically treated alloys.

It has been observed that the LPs of the B19'-martensite formed from highly-dislocated austenite, differ from the corresponding LPs of the martensite formed by quenching from recrystallized austenite [6,8]. As for the martensite LP in nanocrystalline Ti-Ni SMA, they have not yet been studied.

Based on this information, the following questions arise: (1) Are the calculated LPs of the thermal martensite formed in the highly dislocated or nanocrystalline austenites true LPs? And if yes, (2) how do the martensite LPs and maximum transformation lattice strain depend on the austenite dislocation substructure and nanocrystalline structure features?

It is generally assumed that LPs of stress-induced and reoriented martensites are equal to those of coolinginduced ("thermal") martensite. However, some results for stress-induced and reoriented martensites do not confirm this assumption $[11,12]$. A similar discrepancy is related to the LPs of a moderately plastically deformed martensite $[12,13,6]$.

To clarify all of the above problems, an X-ray diffraction study of the martensite LPs and transformation lattice strain in Ti-Ni alloys was conducted.

\section{Experimental Procedure}

Specimens of the Ti-49.73 to 51.05 at\%Ni composition supplied by "Special Metals Co" (USA) were studied. The 1 $\mathrm{mm}$ diameter wires were water-quenched from $700^{\circ} \mathrm{C}$. The Ti-50.26at $\% \mathrm{Ni}$ alloy was subjected to CR with true logarithmic strain e $=0.3$ and 1.9 , and then annealed in the 200 to $500^{\circ} \mathrm{C}(1 \mathrm{hr})$ temperature range. Quenching from $700^{\circ} \mathrm{C}$ served as a reference treatment since it corresponded to a completely recrystallized austenite structure. To obtain the isotropic powder samples, the filings of the quenched $\mathrm{Ti}-50.26 \mathrm{at} \% \mathrm{Ni}$ alloy were sawed and then partially vacuum-annealed at $450^{\circ} \mathrm{C}$.

For experiments with stress-induced, reoriented and moderately plastically deformed martensites, bulk samples $(6 \times 10 \times 15) \mathrm{mm}$ of the Ti-50.0at $\% \mathrm{Ni}$ alloy were used. These samples were quenched from $700^{\circ} \mathrm{C}$ and then subjected to three different treatments: (1) rolling at $150^{\circ} \mathrm{C}$ with residual strain $\varepsilon=4.9 \%$ (stress-induced martensite); (2) RT rolling with residual strain $\varepsilon=5 \%$ (reoriented martensite); and (3) RT rolling with residual strain $\varepsilon=14.5 \%$ (plastically deformed martensite). X-ray diffractograms were taken from three mutually perpendicular surfaces: //RP, $\perp \mathrm{RD}$, and //RD.

The X-ray diffractograms were obtained by means of $\mathrm{Cu} K_{\alpha}$ radiation in the 150 to $-180^{\circ} \mathrm{C}$ temperature range using the "PANalytical X'pert-Pro" diffractometer equipped with a low-temperature camera system, "TTK450+LNC". The LPs $a, b, c$ and $\beta$ angle of the monoclinic B19'-martensite were calculated from the angular peak positions of X-ray lines, as in [6]. The maximum transformation lattice strain (referred to the $\mathrm{M}_{\mathrm{S}}$ temperatures) was calculated from the B19'-martensite and B2-austenite LPs following a procedure described in [6]. The crystallographic direction of maximum lattice strain and maximum transformation lattice strain for polycrystalline austenite were calculated as well.

\section{Results and Discussion}

\subsection{Thermal martensite in quenched Ti-Ni alloys}

Starting from $50.0 \mathrm{at} \% \mathrm{Ni}$, the angular coordinates of the quenched B19'-martensite X-ray lines gradually shift with the nickel concentration increase. These shifts are anisotropic and replicated for any temperature in the $20^{\circ} \mathrm{C}$ to $180^{\circ} \mathrm{C}$ range, thus correlating well with known data [6-8].

Correspondingly, the LPs of B19'-martensite linearly change with nickel concentration in the 50.0 to 51.05 at $\%$ Ni range (Fig. 1). The LPs concentration dependencies are shown in Fig. 1 for $-160^{\circ} \mathrm{C}$. However, they are very similar at any temperature in the studied range: on heating, the values of $a, c$ and $\beta$ angle decrease and $b$ increases.

The martensite X-ray line shifts with nickel concentration are not accompanied by significant X-ray line width changes, as shown for the (002) line in Fig.1. Thus, there is a gradual and not a stepped LP concentration dependence.

The maximum transformation lattice strain for austenite single crystal calculated from the measured martensite and austenite LPs at $\mathrm{M}_{\mathrm{S}}$ decreases linearly from 11.85 to $10.4 \%$ in the nickel concentration range studied 
(see Fig.1), which correlates well with the previous data [6,7]. The transformation lattice strain $\varepsilon_{\max }$ calculated for polycrystalline austenite is somewhat lower than that for single crystal austenite (see Fig.1).
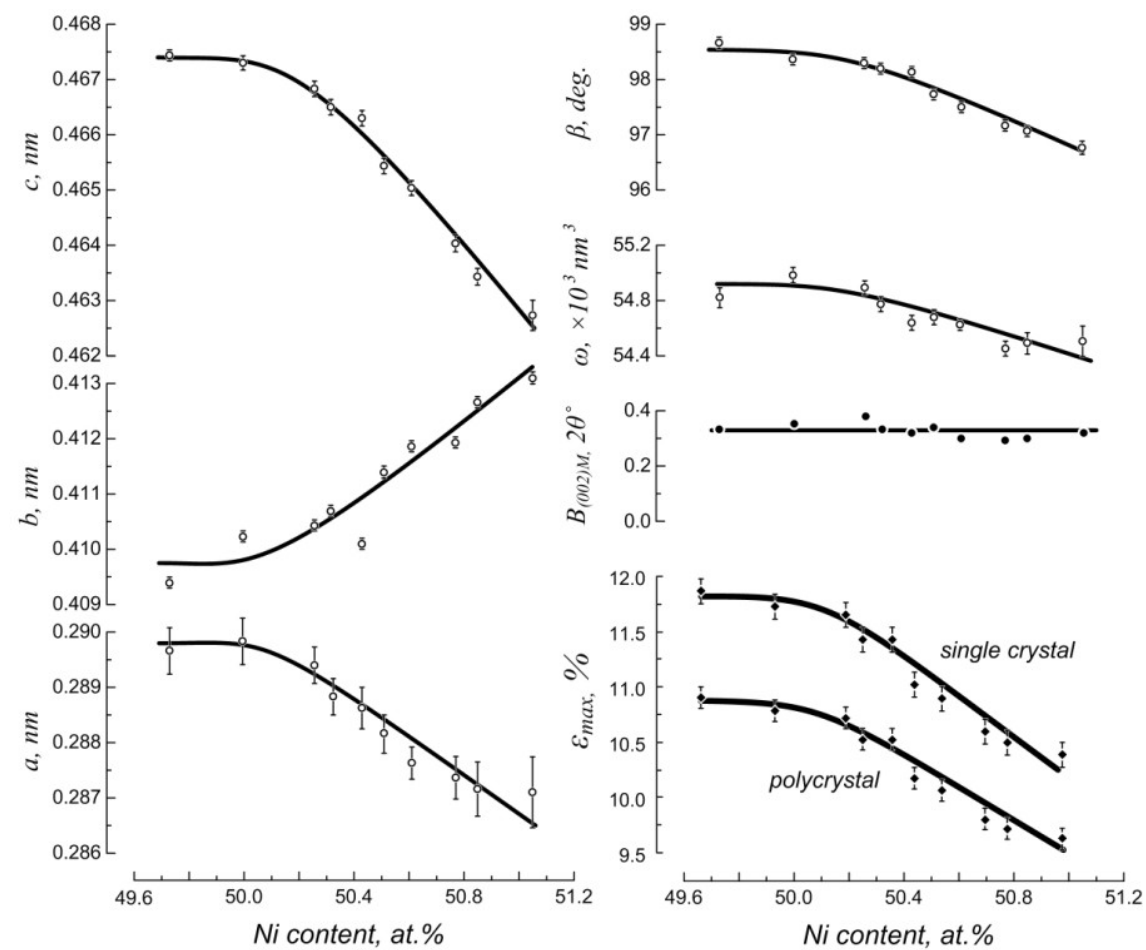

Fig.1. Concentration dependencies of quenched martensite lattice parameters, maximum transformation lattice strain for singlecrystalline and isotropic polycrystalline austenites, and $(002)_{\mathrm{B} 19}, \mathrm{X}$-ray line width in Ti-Ni alloys.

The crystallographic direction of $\varepsilon_{\max }$ is close to $\langle 588\rangle_{\mathrm{B} 2}$ in equiatomic and pre-equiatomic alloys and moves to $\left\langle 122>_{\mathrm{B} 2}\right.$, when nickel concentration increases (Fig.2).

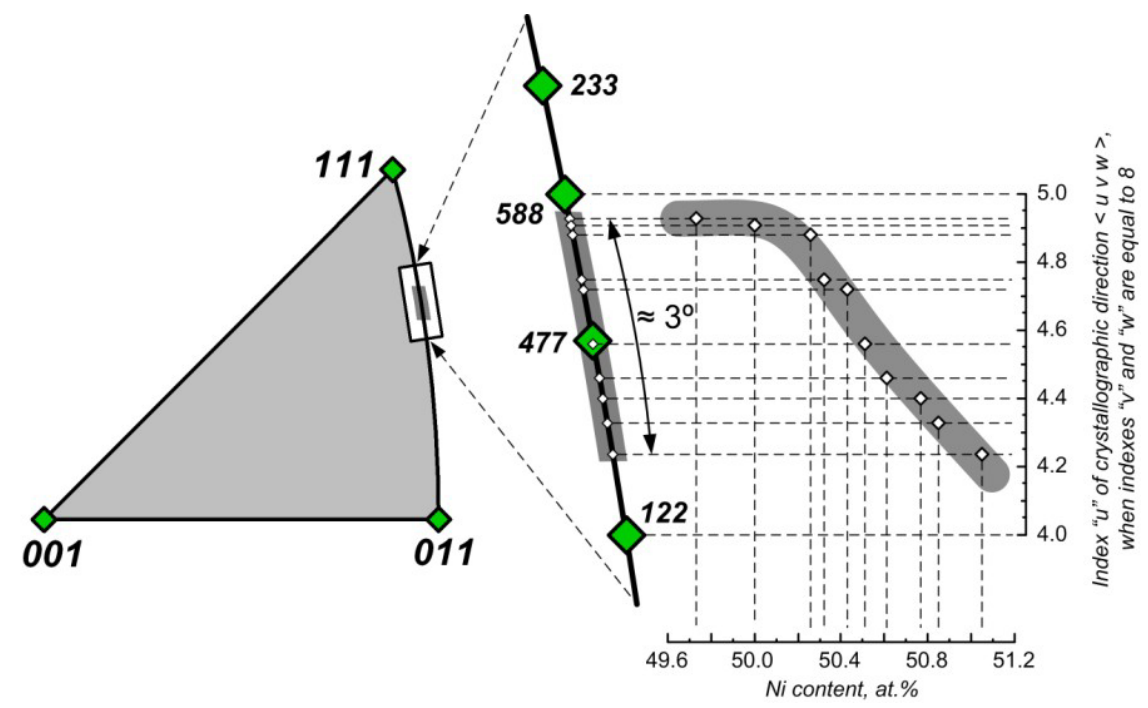

Fig.2. Concentration dependence of the maximum transformation lattice strain direction in quenched Ti-Ni alloys. 


\subsection{Thermal martensite in cold-rolled and annealed Ti-Ni alloys}

The structure formation in the cold-rolled and annealed non-hardenable and hardenable Ti-Ni SMAs was studied in detail for Ti-50.0 and Ti-50.7at\%Ni alloys [9,10]. According to the TEM studies [9,10], a well-developed dislocation substructure of martensite and austenite forms in $\mathrm{Ti}-\mathrm{Ni}$ as a result of a moderate rolling deformation with true strain of $\mathrm{e}=0.3$. A severe plastic deformation, $\mathrm{e}=1.5-2$, leads to the formation of a nanocrystalline austenite mixed with an amorphous structure. Post-deformation annealing (PDA) of the moderately deformed alloy is accompanied by successive recovery, polygonization and subgrain growth in the dislocation substructure followed by recrystallization. On the contrary, PDA of the severely deformed alloy causes nanocrystallization of the amorphous structure and growth of the austenite nanograins.

The PDA behavior of Ti-50.26at\% Ni alloy is similar to that of $\mathrm{Ti}-50.0 \mathrm{at} \% \mathrm{Ni}$, however, all of the annealing processes are slowed down. Thus, according to the TEM study, the austenite grain size in Ti-50.26at\%Ni alloy after severe $\mathrm{CR}$, e $=1.9+\mathrm{PDA}$ at $400^{\circ} \mathrm{C}$ and $450^{\circ} \mathrm{C}$, is about $40-50 \mathrm{~nm}$ and somewhat below $100 \mathrm{~nm}$, respectively, as compared to 65 and $175 \mathrm{~nm}$ for Ti-50.0at\%Ni alloy [10].

An integral estimation of the structure based on the austenite X-ray line width reveals that the increased density of lattice defects or ultra-fine grain size in initially deformed Ti-50.26\%Ni alloy are preserved after PDA below $500^{\circ} \mathrm{C}$.

Comparison of the diffractograms obtained after quenching and after low-temperature annealings of both moderately and severely deformed Ti-50.26at\%Ni alloys reveals regular anisotropic shifts of X-ray lines of the B19'martensite formed in polygonized or nanocrystalline austenites from their positions in quenched martensite formed in recrystallized austenite, which is similar to the results of [6,8] (Fig.3). The lower the PDA temperature, the higher the residual dislocation density and the smaller the subgrain and grain size, the greater the line shifts (see Fig.3).
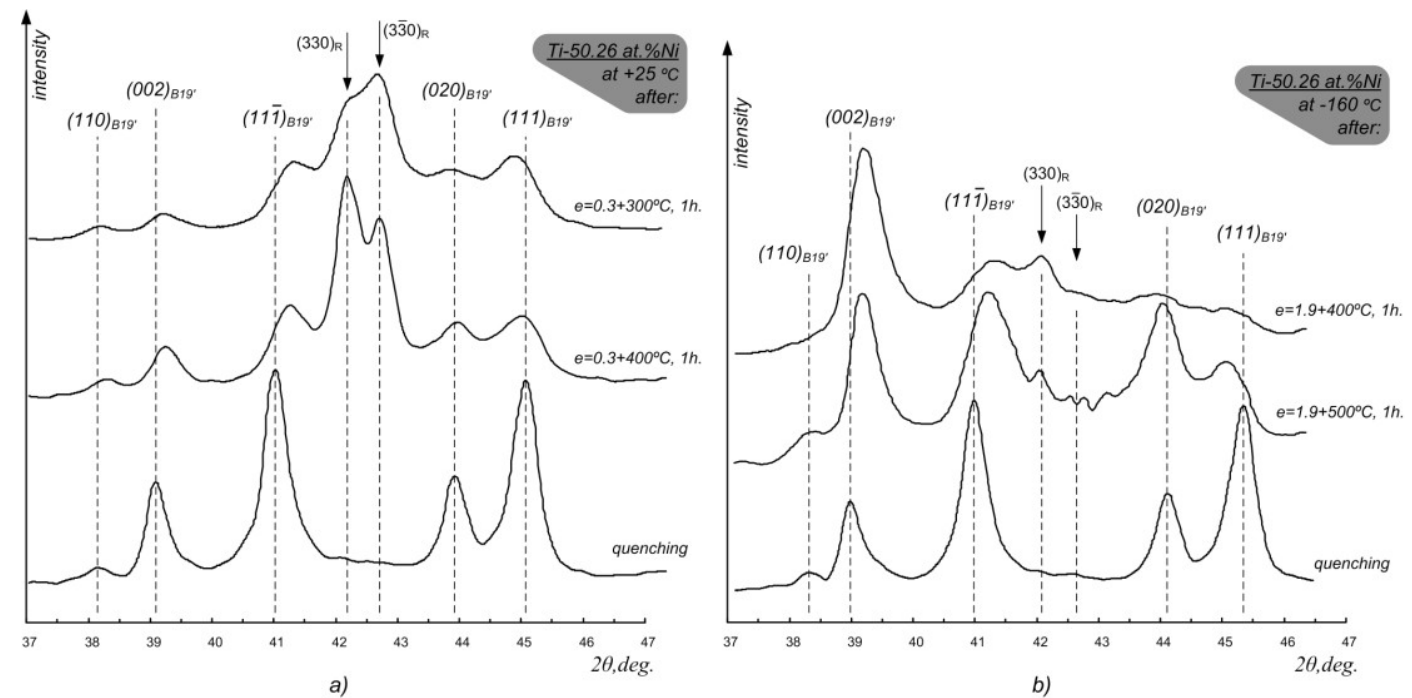

Fig.3. X-ray diffractograms of Ti-50.26 \% Ni alloy obtained after quenching and CR with post-deformation annealing at various temperatures: a) initial $\mathrm{CR}, \mathrm{e}=0.3$, recorded at the $\mathrm{RT}$ (polygonized dislocation substructure of austenite); b) initial $\mathrm{CR}$, $\mathrm{e}=1.9$, recorded at $-160^{\circ} \mathrm{C}$ (nanocrystalline structure of austenite).

In the subzero temperature range, the temperature dependencies of the B19'-martensite X-ray line angular positions are reversible and appear to be independent of the thermomechanical treatment. Upon cooling, the line positions shift in the same directions as shown in [6]: (110), (020) and (111) to higher angles, (002), (11 $\overline{1})$ and $(11 \overline{2})$ shift to lower angles (note that $(11 \overline{2})$ line is beyond the Fig. $32 \theta$ scale).

While the martensite LPs can readily be calculated from the X-ray line coordinates of the thermomechanically treated alloys, the question that arises is: Will the calculated parameters be true or "apparent", i.e., influenced by a possible anisotropy of residual stress fields? To answer this question, isotropic samples were prepared from sawed filings of Ti- $50.26 \% \mathrm{Ni}$ alloy, initially quenched from $700^{\circ} \mathrm{C}$. The heavily strain-hardened filings were then annealed at $450^{\circ} \mathrm{C}$, which resulted in their partial recovery. The experiment with highly-dislocated isotropic samples consisted 
of sawed and partially annealed filings revealed the same line shifts from the positions for quenched martensite. Thus, the calculated martensite LPs should be not apparent, but true parameters.

The calculated LPs of the martensite formed from recovered and polygonized or nanocrystalline austenites differ from the corresponding LPs of the martensite formed from quenched (i.e., recrystallized) austenite. Figure 4 shows that the differences between the thermomechanically processed and quenched martensite LPs increase as the PDA temperature decreases, i.e., with the nanocrystalline grain refinement and with an increase in the residual dislocation density and subgrain refinement.

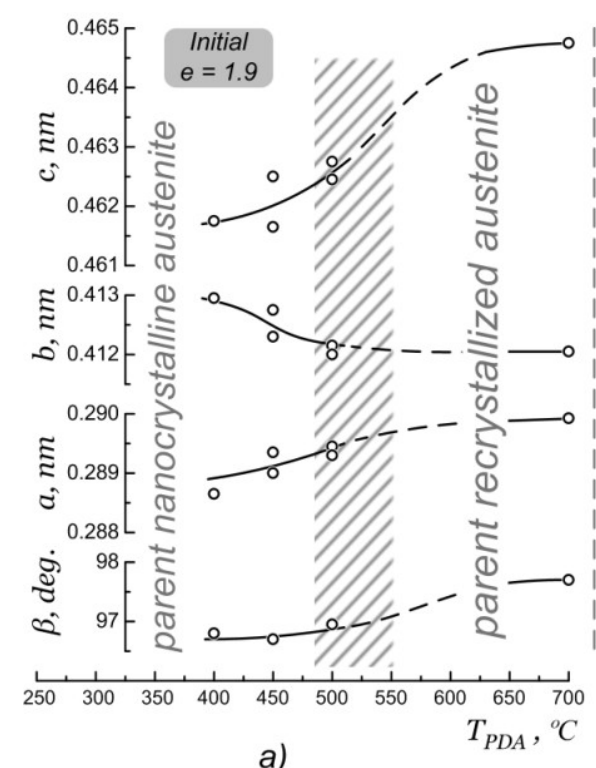

a)

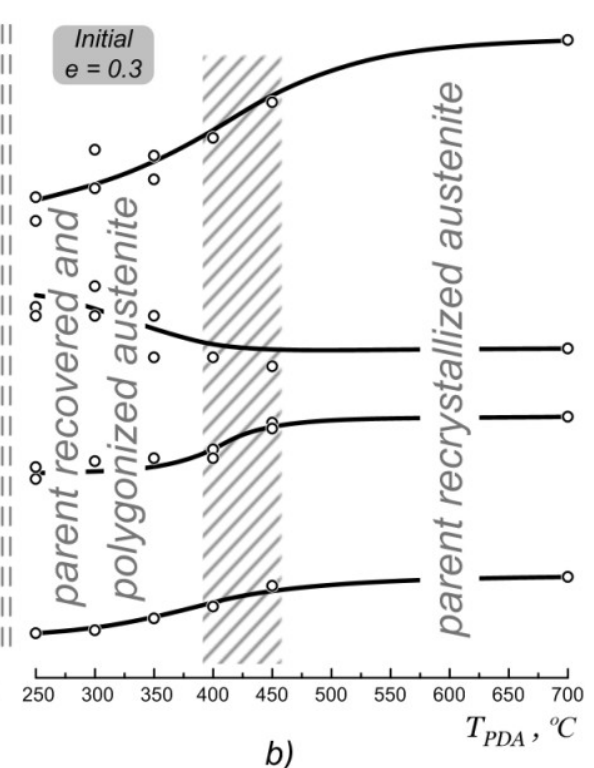

b)

Fig.4. B19'-martensite lattice parameters at RT $v s$ post-deformation annealing temperature for Ti-50.26 \% Ni alloy: a) initial $\mathrm{e}=1.9, \mathrm{~b})$ initial $\mathrm{e}=0.3$.

Figure 5 shows that the maximum martensitic transformation lattice strain $\varepsilon_{\max }$ calculated from the martensite and austenite LPs at $\mathrm{M}_{\mathrm{S}}$ is the highest strain for martensite formed in recrystallized austenite, and it decreases by about $1 \%$ as the post-deformation annealing temperature decreases, i.e., with either nanograin refinement or with an increase in residual dislocation density and subgrain refinement. It should be noted, however, that in practice, the largest completely recoverable strains are obtained in nanocrystalline alloys, whereas the lowest are found, in recrystallized alloys. In other words, the degree of realization of the completely recoverable strain resource is much higher in the nanocrystalline Ti-Ni alloys, because there is a greater difference between the "dislocation" and "transformation" yield stresses $[9,10]$. It should be noted that the $\varepsilon_{\max }$ data in Fig.5 are calculated for the austenite single crystal transformation. For the transformation of polycrystalline austenite, the calculated $\varepsilon_{\max }$ value should be decreased by $7-8 \%$ of the $\varepsilon_{\max }$ value for single crystal austenite (see Fig. 1 ).

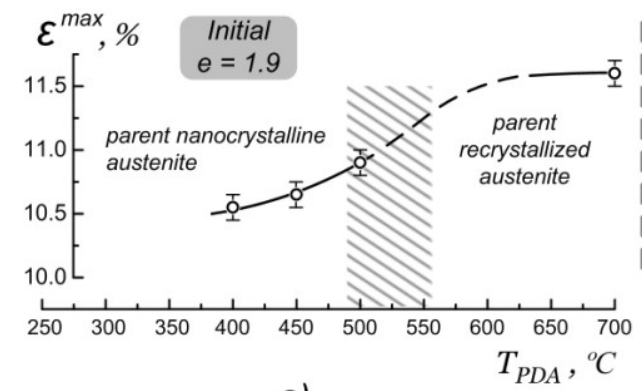

a)

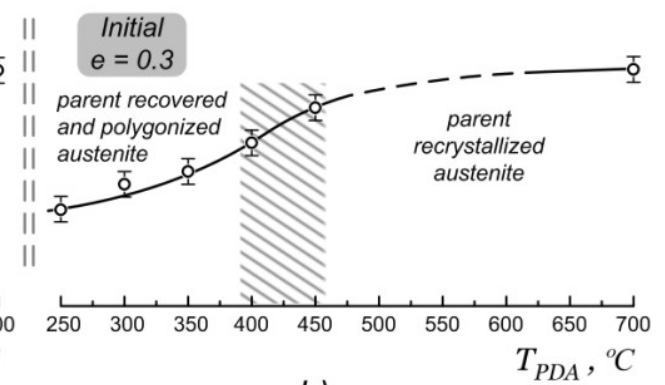

b)

Fig.5. Maximum martensitic transformation lattice strain $v s$ post-deformation annealing temperature for Ti-50.26 \%Ni alloy: a) initial $\mathrm{e}=1.9, \mathrm{~b}$ ) initial $\mathrm{e}=0.3$. 


\subsection{Stress-induced, reoriented and moderately plastically deformed martensites}

To determine the LPs of stress-induced, reoriented and moderately plastically deformed martensites, $6 \mathrm{~mm} \times 10 \mathrm{~mm}$ $\times 15 \mathrm{~mm}$ quenched samples of Ti-50.0at $\% \mathrm{Ni}$ alloy were subjected to three different treatments: (1) rolling at $150^{\circ} \mathrm{C}$ with residual strain $\varepsilon=4.9 \%$ ); (2) rolling at RT with residual strain $\varepsilon=5 \%$; and (3) rolling at RT with residual strain $\varepsilon=14.5 \%$.

Since the deformation of martensite can introduce anisotropic residual stresses, to obtain an objective picture, $\mathrm{X}$-ray diffractograms were taken at three mutually perpendicular surface planes: //RP, $\perp \mathrm{RD}$, and //RD. The experiment shows that the angular coordinates of stress-induced, reoriented and plastically deformed martensite Xray lines and their temperature dependencies are approximately the same as those presented in Fig. 6 for the first one. Comparison with X-ray line coordinates of quenched martensite shows that:

(1) The temperature dependence of $2 \theta_{002}, 2 \theta_{200}$, and $2 \theta_{221}$ for //RP orientation of deformed samples is opposite to that observed after quenching and for $\perp \mathrm{RD}$ (except $\varepsilon=4.9 \%$ ), as well as for $/ / \mathrm{RD}$ orientations of deformed samples.

(2) The temperature dependence of $2 \theta_{111}$ is absent or very weak for $\perp \mathrm{RD}$ orientation, unlike quenching and //RP and //RD orientations of deformed samples.

(3) The $2 \theta_{\mathrm{hkl}}(\mathrm{T})$ curves of deformed samples for some (hkl) lines (for example, (111) and (11 $\left.\overline{2}\right)$ ) are shifted in opposite directions from the corresponding $2 \theta_{\mathrm{hkl}}(\mathrm{T})$ for quenched alloy, as compared to the martensite formed from the thermomechanically treated austenite.
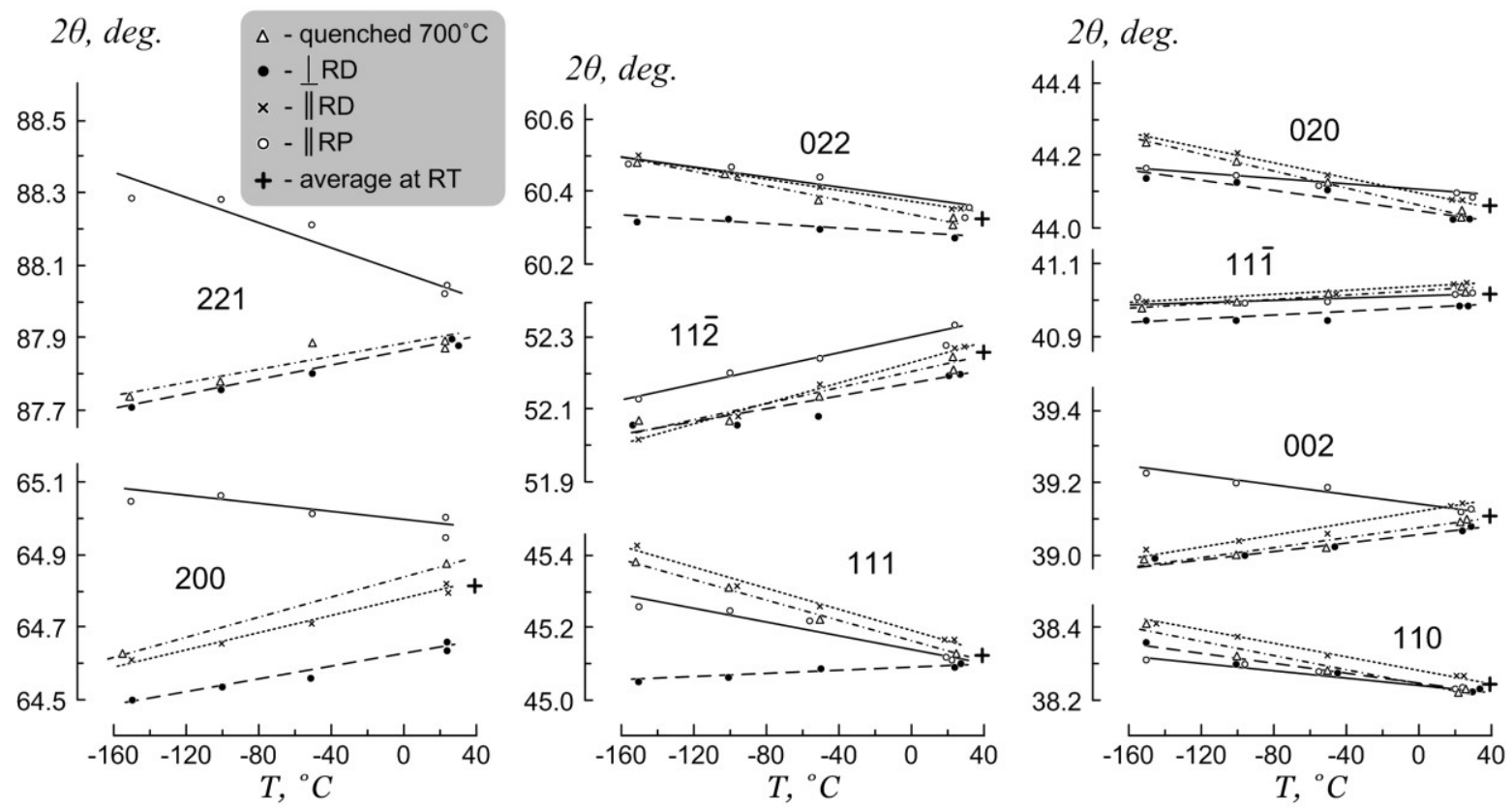

Fig.6. Temperature dependencies of angular co-ordinates of stress-induced B19'-martensite X-ray lines obtained from three mutually perpendicular surfaces of rolled samples of Ti-50.26at $\% \mathrm{Ni}$ alloy.

It follows from Fig. 6 that $2 \theta_{\mathrm{hkl}}$ values averaged over three mutually perpendicular planes for the plastically deformed, stress-induced and reoriented martensites at RT (somewhat below $\mathrm{M}_{\mathrm{f}}$ temperature) are close to the corresponding $2 \theta_{\mathrm{hkl}}$ values of the isotropic quenched sample. The calculated "average" LPs of stress-induced, reoriented and moderately plastically deformed martensites and those of quenched martensite are close to each other. Thus, the transformation lattice strain values do not differ for these cases as well. 


\section{Conclusions}

- The concentration dependence of the B19'-martensite lattice parameters in quenched binary Ti-Ni shape memory alloys is linear in the 50 to 51 at $\% \mathrm{Ni}$ range, and there is no discrete transition from one martensite lattice to another with different parameters. The maximum transformation lattice strain at $\mathrm{M}_{\mathrm{S}}$ linearly decreases from 11.85 to $10.4 \%$ for austenite single crystal, and from 10.9 to $9.65 \%$ for polycrystalline austenite in the same concentration range. The direction of maximum transformation lattice strain changes from the 50 to 51 at.\% $\mathrm{Ni}$ concentration range from $\langle 588\rangle_{\mathrm{B} 2}$ towards $\langle 122\rangle_{\mathrm{B} 2}$.

- The lattice parameters of cooling-induced B19'-martensite formed in polygonized or nanocrystalline B2austenites differ from the corresponding parameters of the martensite formed in quenched (recrystallized) austenite. This difference increases as the PDA temperature decreases, i.e., with the nanocrystalline grain refinement, increase in residual dislocation density, and with the subgrain refinement in the austenite.

- The maximum martensitic transformation lattice strain, i.e., a theoretical limit for recovery strain, is highest for the martensite formed in recrystallized austenite, and it decreases by about $1 \%$ with grain refinement within a nanoscale range, and with an increase in residual dislocation density and subgrain refinement.

- The average lattice parameters of stress-induced, reoriented and moderately plastically deformed martensites calculated at RT for the //RP, $\perp \mathrm{RD}, \perp \mathrm{RP}$ planes are close to the quenched martensite LPs, thus indicating their average transformation strain equality.

The present work was carried out under financial support from the Federal Program "Development of Scientific Potential of Higher School" of the Ministry of Education and Science of the Russian Federation, from the Natural Science and Engineering Research Council of Canada (NSERC) and by the Fonds de recherche sur la nature and les technologies du Québec (FQRNT).

\section{References}

[1] Engineering aspects of shape memory alloys. T.W.Duerig, K.N.Melton, D.Stockel, C.M.Wayman, editors (Butterworth-Heinemann, London, 1990), p.499.

[2] Shape memory materials. K.Otsuka, C.M.Wayman, editors (Cambridge Univ. Press, Cambridge, 1998), p.284.

[3] Shape memory alloys: fundamentals, modeling and applications. V.Brailovski, S.Prokoshkin, P.Terriault, F.Trochu, editors (ETS Publ., Montreal,2003), p.851.

[4] K.Otsuka, T.Sawamura, K.Shimizu, Phys. Stat. Sol. (a) 5, 457 (1971)

[5] Y.P.Mironov, S.N.Kulkov, Izv. VUZov. Fizika 8, 49 (1994) (in Russian).

[6] S.D.Prokoshkin, A.V.Korotitskiy, V.Brailovski V et al., Acta Mater. 524479 (2004)

[7] S.D.Prokoshkin, A.V.Korotitskiy, V.M.Gundyrev, V.I.Zeldovich,. Mater. Sci. Eng. A 481-482, 489 (2008)

[8] S.D.Prokoshkin, V.Brailovski, S.Turenne et al., J. Phys. IV 112, 651 (2003)

[9] V.Brailovski, S.D.Prokoshkin, I.Y.Khmelevskaya et al., Mater. Trans. JIM 47, 795 (2006)

[10] S.D.Prokoshkin, V.Brailovski, K.E.Inaekyan et al., Mater. Sci. Eng. A 481-482, 114 (2008)

[11] H.Sitepu, W.W.Schmahl, R.B.Von Dreele, Appl. Phys. A 74(Suppl.), 1676 (2002)

[12] S.N.Kulkov, Y.P.Mironov, Nucl. Instr. Meth. Phys. Res. A 359, 165 (1995)

[13] T.Tadaki, C.M.Wayman, Scripta Met. 14, 911 (1980) 